удк 631.445.24.631.4161

https://doi.org/10.32634/0869-8155-2020-342-10-88-91

Тип статьи: Оригинальное исследование

Type of article: Original research

Гахраманова Рамиля Фируддин кызы

Азербайджанский Государственный Аграрный Университет г. Гянджа, Азербайджан qehremanova1977@mail.ru

Ключевые слова: хлопчатник, ячмень, озимый горох, фаза роста, фазы развития

Для цитирования: Гахраманова Р.Ф. Сравнительная характеристика влияния минеральных удобрений и сидератов на фазы роста и развития хлопчатника. Аграрная наука. 2020; 342 (10): 88-91.

https://doi.org/10.32634/0869-8155-2020-342-10-88-91

Конфликт интересов отсутствует

Ramila F. Gakhramanova

Azerbaijan State Agrarian University, Ganja, Azerbaijan

qehremanova1977@mail.ru

Key words: cotton, barley, winter peas, growth phase, development phases

For citation: Gakhramanova R.F. Comparative characteristics of the influence of mineral fertilizers and green manures on the growth and development phases of cotton. Agrarian Science. 2020; 342 (10): 88-91. (In Russ.)

https://doi.org/10.32634/0869-8155-2020-342-10-88-91

There is no conflict of interests

Сравнительная характеристика влияния минеральных удобрений и сидератов на фазы роста и развития хлопчатника

\title{
PEЗЮME
}

Актуальность. Хлопок является стратегически важной технической культурой. Волокно, его основной продукт, пользуется постоянным спросом на мировом рынке. Одним из наиболее важных факторов получения стабильного и высокого урожая хлопка является плодородие почвы. Основной целью исследования является разработка эффективных альтернативных агротехнических приемов для повышения плодородия почвы и получения из хлопчатника высококачественного продукта без использования удобрения в слабо обеспеченных серо-коричневых (каштановых) почвах в Гянджа-Газахском районе Азербайджанской Республики.

Результаты. Впервые в ходе исследования были выявлены роль сидератов, для производства высококачественного хлопкового сырья из сортов хлопчатника Гянджа-114 на орошаемых серо-коричневых (каштановых) почвах. Благодаря влиянию сидератов, улучшились агрохимические, водно-физические свойства почвы и повысились показатели продуктивности и качества продукции хлопчатника.

\section{Comparative characteristics of the influence of mineral fertilizers and green manures on the growth and development phases of cotton.}

\begin{abstract}
Relevance. Cotton is a strategically important technical crop. Fiber, its main product, is in constant demand in the global market. One of the most important factors in obtaining a stable and high yield of cotton is soil fertility. The main goal of the study is to develop effective alternative agrotechnical methods to increase soil fertility and obtain a highquality product from cotton without the use of fertilizer in poorly supplied gray-brown (chestnut) soils in the Ganja-Gazakh region of the Republic of Azerbaijan.

Results. For the first time in the course of the study, the role of green manure was revealed for the production of high-quality cotton raw materials from the Ganja-114 cotton varieties on irrigated gray-brown (chestnut) soils. Thanks to the influence of green manure, the agrochemical, water-physical properties of the soil improved and the indicators of productivity and quality of cotton products increased.
\end{abstract}




\section{Введение}

Хлопок является стратегически важной технической культурой. Волокно, его основной продукт, пользуется постоянным спросом на мировом рынке. Одним из наиболее важных факторов получения стабильного и высокого урожая хлопка является плодородие почвы.

В сегодняшнем глобализированном мире существует потребность в новых системах биологического земледелия в сельском хозяйстве. Многолетние научно-исследовательские работы, проведенные в системе земледелия, показывают, что при возделывании сельскохозяйственных культур, особенно хлопчатника, не используя минеральные удобрения, пестициды, гербициды, можно получить высокие урожаи и повысить плодородие почвы за счет органиков.

Таким образом, для получения экологически чистых продуктов в сельском хозяйстве с точки зрения защиты окружающей среды и почвы, разработка альтернативных систем земледелия и новых технологий выращивания является одной из актуальных проблем.

Цель работы. Учитывая актуальность проблемы, основной целью исследования является разработка эффективных альтернативных агротехнических приемов для повышения плодородия почвы и получения из хлопчатника высококачественного продукта без использования удобрения в слабо обеспеченных серо-коричневых (каштановых) почвах в Гянджа-Газахском районе Азербайджанской Республики.

Впервые в ходе исследования были выявлены роль сидератов для производства высококачественного хлопкового сырья из сортов хлопчатника Гянджа-114 на орошаемых серо-коричневых (каштановых) почвах.

Благодаря влиянию сидератов, улучшились агрохимические, водно-физические свойства почвы и повысились показатели продуктивности и качества продукции хлопчатника.

\section{Методика}

Исследовательская работа была проведена на опытном поле Гянджинского Регионального Аграрно-Научного и Информационно-Консультационного Центра.

В качестве исследовательского материала был использован сорт Гянджа-114. Посев проведен в 6 вариантах, повторность 4-кратная, площадь каждой делянки составила 96 м² $^{2}(40 \times 2,4$ м), посев был проведен рядовым (ленточным) способом со схемой посева 60 × 15 см.

Было посеяно $100 \mathrm{kг/га} \mathrm{ячменя,} 60$ кг/га озимого гороха. Из минеральных удобрений азот был внесен в виде аммиачной селитры (34,7\%), фосфор - в виде суперфосфата $(18,7 \%)$ и калий - в виде сульфата калия (46\%), 80\% фосфора и калия были внесены под вспашку, остальные 20\% в подкормку, а азот был внесен 2 раза в виде подкормки.

Схема полевого опыта следующая:

1. Контроль (каждый год гузапаи выводится из участка).

2. $\mathrm{N}_{90} \mathrm{P}_{120} \mathrm{~K}_{90}$ (каждый год гузапаи выводится из участка).

3. Каждый год гузапаи измельчается и вносится под вспашку.

4. Перед последним вегетативным поливом проводят посев ячменя в междурядье хлопчатника, и в декабре вся надземная часть вместе с гузапаи измельчается и вносится в подпахотный слой и весной проводится посев хлопчатника;

5. Перед последним вегетативным поливом проводят посев озимого гороха в междурядье хлопчатника, и в декабре вся надземная часть вместе с гузапаи измельчается и вносится в подпахотный слой и весной проводится посев хлопчатника.

6. Перед последним вегетативным поливом проводят смешанный посев озимого гороха с ячменем в междурядье хлопчатника, и в декабре вся надземная часть вместе с гузапаи измельчается и вносится под вспашку и весной проводится посев хлопчатника.

В исследованиях Г.А. Асланова и Т.А. Гасановой в Самухском районе Азербайджана изучалось влияние минеральных удобрений на рост и развитие, показатели урожайности и качества растений хлопчатника в севообороте.

Исследования показывают, что рост и развитие растений зависят от плодородия почвы. Наилучшие показатели наблюдали в варианте $\mathrm{N}_{60} \mathrm{P}_{120} \mathrm{~K}_{90}$, где высота растения составляла 112,6 см; количество симподиальных ветвей - 17,5; масса коробочек на одном кусте составила 121,6 г. Влияние повышенных норм минеральных удобрений ( $\left.\mathrm{N}_{90} \mathrm{P}_{150} \mathrm{~K}_{120}\right)$ на изученные показатели хлопчатника было ниже, чем у $\mathrm{N}_{60} \mathrm{P}_{120} \mathrm{~K}_{90}$ и составило соответственно: 105,4 см, 14,2 и 16,6 шт.; 118,3 г. По сравнению с контрольным (без удобрения) вариантом благодаря действию минеральных удобрений высота растения увеличилось на 3,2-20,3 см; количество симподиальных ветвей 1,3-5,3; количество коробочек на одной ветви - на1,1-4,8 шт.; а масса 1000 семян - на 3,3-11,1г[1].

Согласно исследованиям Т.Д. Токаревой в Астраханской области России, повышенные нормы азотных удобрений $\left(\mathrm{N}_{150} \mathrm{P}_{80} \mathrm{~K}_{40}\right)$ увеличивают высоту хлопчатника, количество листьев и веток, а также расстояние между плодоносными ветвями [9].

В исследованиях, проведенных Ф.Н. Пирохуновой в Узбекистане, добавление микроэлементов - меди, бора и их смеси со стимулятором диацетатмоноэтаноламина к основным удобрениям увеличивает высоту сортов хлопчатника Бухара-12 и Омад, количество почек и цветков во время массовых фаз распускания и цветения [5].

Многие авторы в своих исследованиях с хлопчатником особенно подчеркивают влияние обработки почвы, междурядных обработок, времени сева, режима орошения и удобрений на накопление сухого вещества в хлопке, рост и развитие растений хлопчатника, продуктивность и качество продукции $[12,13,14]$

Исследования, проведенные в Ставропольском крае, показывают, что количество органического вещества в почве за последние 25-30 лет уменьшилось на 25-30\%. Основные причины этого - интенсивное механическое вмешательство в почву: вспашка, дискование, обработка почвы, боронование и т.д. В конечном итоге это приводит к нарушению процесса аэрации, структуры почвы и образованию большего количества пылевых фракций. В результате ослабевают водопоглощающие и водоудерживающие свойства почвы, усиливается процесс минерализации органических веществ и усиливаются такие процессы, как эрозия почвы и дефляция [2].

По мнению Н.А. Максютовой и Г.А. Кремера, зеленые удобрения повышают плодородие почвы, повышают содержание органических веществ, снижают вынос питательных веществ в нижние горизонты и замедляют минерализацию гумуса [3].

В настоящее время в исследованиях Н.В. Шрамко, Г.В. Вихаровой, Д.О. Дмитриева и В.М. Новикова актуальным является использование органических веществ для повышения плодородия бедных питательными веществами почв Верхнего Поволжья. Решение этой про- 
блемы возможно в основном с использованием сидератов растений, многолетних трав и соломы [10; $11 ; 4]$.

Исследования, проведенные И.Д. Сосниной в Пермском крае России в системе 7-польного севооборота, показали, что сидераты растений оказывают значительное влияние на урожайность сельскохозяйственных культур и плодородие почвы и, как следствие, устраняют отрицательный баланс гумуса [7].

По мнению многих российских авторов, в период экономического и энергетического кризиса с помощью различных агрофакторов можно получить экологически чистые продукты полностью биологическим путем и по невысокой цене. В связи с этим очень важен переход к научно обоснованной и адаптированной системе земледелия [6].

По данным исследований Г.А. Тарова, смешанные культуры соломы, рапса, гороха и других растений накапливают за вегетационный период 3,7-7,0 т / га сухой массы, а в почву поступает 344-520 кг/га питательных веществ. В результате повышается эффективное плодородие почвы [8].

Изучено влияние органиков и минеральных удобрений на фазы роста и развития растений хлопчатника в 2017-2018 годах. В контрольном варианте, в фазе бутонизации, высота растения составляла соответственно: 19,1-20,3 см, симподиальных ветвей 3,8-4,1 шт., цветки 3,5-3,8 шт.; высота при цветении 28,8-30,5 см, симподиальные ветви 6,8-7,3 шт., цветки 7,3-7,8 шт., коробочки 3,1-3,3 шт.; в фазе полного созревания высота растения составляла 80,5-85,3 см, симподиальные ветви - 9,8-10,3 шт., коробочки - 5,0-5,3 шт.; распустившие коробочки 3,8-4,1 шт.

В вариантах с применением минеральных удобрений и сидератов показатели роста и развития растений значительно увеличивались.

Так, во 2 варианте в фазе бутонизации высота растения составляла соответственно: $32,5-33,8$ см, симподиальных ветвей - 6,4-6,7 шт., цветки - 6,3-6,5 шт.; высота при цветении - 48,3-49,7 см, симподиальные ветви - 10,7-11,1 шт., цветки - 12,4-12,8 шт., коробочки - 5, 1-5,4 шт.; в фазе полного созревания высота растения составляла 106,5-110,5 см, симподиальные ветви - 16,1-16,8 шт., коробочки - 8,3-8,7 шт.; распустившиеся коробочки - 6,1-6,5 шт.

В 3 варианте в фазе бутонизации высота растения составляла соответственно: 23,0-23,6 см, симподиальных ветвей - 4,3-4,6 шт., цветков - 4,2-4,5 шт.; высота при цветении - 33,7-36,8 см, симподиальные ветви - 7,57,8 шт., цветки - 8,7-9,1 шт., коробочки - 3,7-4,1 шт.; в фазе полного созревания высота растения составляла

\section{ЛИТЕРАТУРА}

1. Асланов Х.А., Гасанова Т.А. Влияние минеральных удобрений на высоту и развитие хлопчатника в следующем севообороте. Институт почвоведения и агрохимии НАНА, Баку: Наука, 2013;21(3):30-34.

2.Желтопузов В.Н., Дубина В.В., Шабалдас О.Г. Зависимость урожайности и качества зерна озимого ячменя от условия возделывания. Вестник АПК Ставрополья. 2012;(3):24-27

3.Максютов Н.А., Кремер Г.А. Сидераты защищают почву от эрозии и повышают плодородие. Земледелие. 1997;(2):27-28

4. Новиков В.М. Влияние элементов интенсификации растениеводства на продуктивность культур в звенях севооборотов. Земледелие. 2015;(4):13-15.

5.Пирохунова Ф.Н. Действие микроэлементов и стимулятора диацетатмоноэтаноламина на рост хлопчатника. Аграрная наука. 2013;(10):19-20.

6. Пигорев И.Я., Солошенко В.М., Наумкин В.Н., Наумкин А.В., Хлопяников А.М., Хлопяникова Г.В. Об инновационных
90,6-93,6 см, симподиальные ветви - 11,4-11,8 шт., коробочки - 5,8-6,1 шт.; распустившиеся коробочки 4,5-4,9 шт.

В 4 варианте в фазе бутонизации высота растения составляла соответственно: 25,7-26,6 см, симподиальные ветви - 5,2-5,4 шт., цветки - 4,9-5,1 шт.; высота при цветении - 39,4-41,8 см, симподиальные ветви 8,6-9,1 шт., цветки - 9,9-10,5 шт., коробочки - 4,24,5 шт.; в фазе полного созревания высота растения составляла 94,6-98,3 см, симподиальные ветви - 12,813,3 шт., коробочки - 6,6-6,8 шт.; распустившиеся коробочки - 5,2-5,6 шт.

В 5 варианте в фазе бутонизации высота растения составляла соответственно: 28,0-29,5 см, симподиальные ветви - 5,4-5,7 шт., цветки - 5,2-5,5 шт.; высота при цветении - 42,1-43,7 см, симподиальные ветви 9,3-9,7 шт., цветки - 10,8-11,6 шт., коробочки - 4,64,9 шт.; в фазе полного созревания высота растения составляла 100,3-103,5 см, симподиальные ветви 14,1-14,8 шт., коробочки - 7,3-7,8 шт.; распустившиеся коробочки - 5,6-6,0 шт; в фазе бутонизации высота растения составляла соответственно: 30,5-31,7 см, симподиальные ветви - 6,2-6,3 шт., цветки - 5,86,3 шт.; высота при цветении - 46,7-47,3 см, симподиальные ветви - 10,4-11,1 шт., цветки - 11,7-12,0 шт., коробочки - 5,1-5,4 шт.; в фазе полного созревания высота растения составляла 105,6-108,6 см, симподиальные ветви - 15,6-16,5 шт., коробочки - 8,1-8,7 шт.; распустившиеся коробочки - 6,2-6,5 шт.

\section{Выводы}

Таким образом, закопанная в почву биомасса и внесенные минеральные удобрения оказывают значительное влияние на рост и развитие хлопчатника в период фазы развития. Во 2 варианте $\left(\mathrm{N}_{60} \mathrm{P}_{120} \mathrm{~K}_{90}\right)$ в конце вегетации прибавка по сравнению с контролем по годам составила: высота растения - 25,2-26,0 см, симподиальные ветви - 6,3-6,5 шт., коробочки - 3,3-3,4 шт.; распустившие коробочки - 2,3-2,4 шт, а в 6 (горох + ячмень) высота растения - 20,3-28,1 см, симподиальные ветви - 5,3-6,7 шт., коробочки - 2,8-3,7 шт.; распустившие коробочки - 2,1-2,7 шт.

Под влиянием сидератов и минеральных удобрений существует сильная корреляция между высотой (см) и сырым продуктом хлопчатника (ц/га) $p=+0,994 \pm 0,005$, $r=+0,975 \pm 0,010$; между сырым продуктом хлопчатника и симподиальными ветвями $p=+0,993 \pm 0,006$, $r=+0,993 \pm 0,006$; между сырым продуктом хлопчатника и коробочкой в одном растении $p=+0,979 \pm 0,020$, $r=+0,987 \pm 0,011$ и эти отношения изменились с годами.

технологиях в земледелии. Вестник Курской государственной сельскохозяйственной академии. 2016;(3):32-36.

7. Соснина И.Д. Влияние видов органических и минеральных удобрений на урожайность зерновых, продуктивность пашни и сохранение плодородия почвы. Достижения науки и техники АПК. 2013;(5):32-35.

8. Сатаров Г.А. Эффективное плодородие почв и применение зеленых удобрений для его улучшения. Ульяновский медико-биологический журнал. 2014;(1):148-153.

9.Токарева Т.Д. Эффективность удобрений при выращивании хлопчатника в Астраханской области. Земледелие. 2013;(7):22-24.

10. Шрамко Н.В., Вихорева Г.В. Рациональное использование приемов биологизации на дерново-подзолистых в системе земледелия Верхневолжья. Зернобобовые и крупяные культуры. 2015;2(14):71-76.

11. Шрамко Н.В., Вихорева Г.В. Рациональное использование паров и приемов биологизации в условиях Верхневолжья. 
Земледелие. 2015;(6):23-25

12.Dhonde P.W., Khade K.K. Performance of cotton varieties under sowing dates and plant population. J.Maharashtra agr.Univ. 1988;13(1):105-106.

13.Guinn. Irrigation Scheduling and plant population effects on

\section{REFERENCES}

1. Aslanov Kh.A., Hasanova T.A. The effect of mineral fertilizers on the height and development of cotton in the next crop rotation. Institute of Soil Science and Agrochemistry of ANAS, Baku: Nauka. 2013; 21(3):30-34. (In Russ.)

2.Zheltopuzov V.N., Dubina V.V., Shabaldas O.G. Dependence of yield and grain quality of winter barley on the cultivation conditions. Bulletin of the agro-industrial complex of Stavropol. 2012;(3):2427. (In Russ.)

3.Maksyutov H.A., Kremer G.A. Siderata protect the soil from erosion and increase fertility. Agriculture. 1997;(2):27-28. (In Russ.)

4. Novikov V.M. The influence of the elements of the intensification of crop production on the productivity of crops in the links of crop rotation. Agriculture. 2015;(4):13-15. (In Russ.)

5.Pirokhunova F.N. Effect of microelements and diacetatemonoethanolamine stimulant on cotton growth. Agrarian science. 2013;(10):19-20. (In Russ.)

6. Pigorev I.Ya., Soloshenko V.M., Naumkin V.N., Naumkin A.V., Khlopyanikov A.M., Khlopyanikova G.V. On innovative technologies in agriculture. Bulletin of the Kursk State Agricultural Academy. 2016;(3):32-36. (In Russ.)

7. Sosnina I. D. Influence of types of organic and mineral fertilizers on grain yield, arable land productivity and preservation growth, bloom rates, boll abscissin, and yield of cotton. Agron. J. $1981 ;(733): 529-534$.

14. Kohel R.J., benedict C.R. Year effects on pardoning of dry matter into cotton ball components. Crop Sci.Soc.America. 1984;24(2):268-270.

of soil fertility. Achievements of science and technology of the agro-industrial complex. 2013;(5):32-35. (In Russ.)

8. Satarov G.A. Effective soil fertility and the use of green fertilizers to improve it. Ulyanovsk medical and biological journal. 2014;(1):148-153. (In Russ.)

9.Tokareva T.D. The effectiveness of fertilizers in the cultivation of cotton in the Astrakhan region. Agriculture. 2013;(7):22-24. (In Russ.)

10. Shramko N.V., Vikhoreva G.V. Rational use of biologization techniques on sod-podzolic crops in the farming system of the Upper Volga region. Legumes and cereals. 2015;2(14):71-76. (In Russ.)

11. Shramko N.V., Vikhoreva G.V. Rational use of vapors and biologization techniques in the conditions of the Upper Volga region. Agriculture. 2015;(6):23-25. (In Russ.)

12.Dhonde P.W., Khade K.K. Performance of cotton varieties under sowing dates and plant population. J.Maharashtra agr.Univ. 1988;13(1):105-106.

13.Guinn. Irrigation Scheduling and plant population effects on growth, bloom rates, boll abscissin, and yield of cotton. Agron. J. $1981 ;(733): 529-534$.

14.Kohel R.J., benedict C.R. Year effects on pardoning of dry matter into cotton ball components. Crop Sci.Soc.America. 1984;24(2):268-270.

ABOUT THE AUTHOR:

Ramila F. Gakhramanova, doctoral student

\section{НОВОСТИ•НОВОСТИ•НОВОСТИ•НОВОСТИ॰}

\section{В Волгоградской области развивают производство самого северного в мире хлопчатника}

Уборка хлопка ведется на опытных полях Волгоградского государственного аграрного университета. Регион является самой северной территорией, где выращивают эту культуру и изучают возможность ее распространения в других районах страны. В настоящее время здесь опробуется выращивание нескольких сортов, которые были специально выведены для условий длинного светового дня. При этом средняя урожайность - около двух тонн с гектара, примерно такая же, как и в Узбекистане, где эта культура получила широкое распространение.

Как сообщает пресс-служба вуза, на базе университета проведена Международная научно-практическая конференция Инновации в развитии хлопководства: достижения и перспективы с участием ученых семи стран. Обсуждались вопросы развития отрасли, селекции, агротехники хлопчатника и защиты его посевов от вредителей и болезней. Работу по селекции и интродукции сортов хлопчатника для условий юга России университет проводит с 2014. И за это время получен положительный результат: созданы два новых сорта ПгССХ 1 и ПгССХ 7 для выращивания в Волгоградской области, разрабатываются элементы технологии возделывания для светло-каштановых почв. В университете работает центр прикладной генетики и селекции хлопчатника.

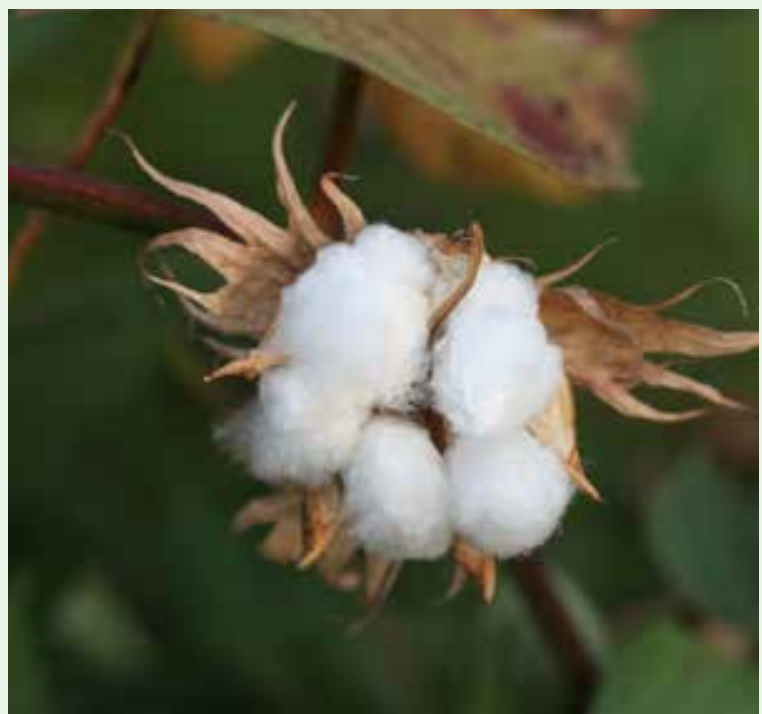

На конференции отмечалось, что опыт выращивания хлопчатника на светло-каштановых почвах доказал возможность производства высококачественного волокна из волгоградских сортов. Их волокно по характеристикам соответствует требованиям ГОСТа «Волокно хлопковое. Технические условия».

Собранный урожай 2020 года будет подвергнут первичной обработке и отправлен на Камышинский хлопчатобумажный комбинат, где хлопок принимают по цене 150 тыс. рублей за тонну. 